\title{
Violência doméstica: uma contribuição da psicanálise
}

\author{
Violence in the family: a psychoanalytical contribution
}

Vera Lúcia C. Lamanno- Adamo 1

\footnotetext{
1 Membro associado da Sociedade Brasileira de Psicanálise de São Paulo; professora responsável pelo Curso de Extensão "Noções Teóricas e Práticas sobre Terapia Família e Casal", Universidade Estadual de Campinas. Rua Duque de Caxias, 642/101 13015-311, Campinas, SP.
}

\begin{abstract}
This article intends to understand family violence based on concepts developed by psychoanalysis. Violence, in this context, is understood as a physical expression of love and hate, disconnected from interest in life and in truth. When it happens, emotional experience appears in a wild and terrifying state. Unconscious structures which accomodate a vicious dynamic between violence and defence against recognizing it are discussed. This paper also stresses the need for an adequate professional trainning in order to help the reconstitution of mental functions which link emotional experiences to growth and development.
\end{abstract}

Key words Psychoanalysis; Violence; Growth; Development
Resumo Este trabalho busca compreender a violência doméstica fundamentada em conceitos desenvolvidos pela psicanálise. Entende-se violência como a expressão física, tanto do amor como do ódio, quando desvinculados do interesse pela vida e pela verdade e, portanto, se apresentando em estado selvagem e apavorante. Discutem-se as estruturas inconscientes nas quais pode repousar uma dinâmica viciosa entre violência e defesa contra reconhecê-la e a importância de formação adequada de profissionais no sentido de que haja uma recuperação das funções mentais que propiciam vincular experiências emocionais com desenvolvimento e crescimento.

Palavras-chave Psicanálise; Violência; Crescimento e Desenvolvimento 


\section{Introdução}

A psicanálise tem mostrado como a apropriação pelo sujeito de seu corpo, de sua identidade sexual e de sua mente, constrói-se a partir de uma intersubjetividade. Winnicott (1985) e Bion (1962) enfatizaram o papel vital de mediação que os pais desempenham para tornar produtivo na criança o desenvolvimento da imagem corporal, do senso de identidade e do pensamento simbólico. Um ambiente que não se ajusta adequadamente à urgente sensação de um recém-nato pertencer a uma dinâmica familiar, que não propicia discriminar fatos de fantasias, contribui para o desenvolvimento de indivíduos que sofrem de constantes ameaças de desintegração do ego. Desenvolve-se então um sistema de defesas altamente organizado e vigorosamente mantido, onde predominam a repressão, a negação e a recusa, com o objetivo de proteger o ego da ansiedade excessiva produzida pelo contato com uma experiência que não pode ser assimilada. Para proteger o ego da ansiedade excessiva, o indivíduo distorce seu contato com a realidade, obstruindo o acesso à consciência e eliminando os conteúdos mentais afetivos e ideativos. Está assim estruturado um campo fértil para a proliferação da violência. Entendo aqui violência, como a expressão física tanto do amor como do ódio, desvinculados do interesse pela vida e pela verdade (Bion, 1992a) e, portanto, apresentando-se em estado selvagem e apavorante.

Money-Kyrle (1971) propõe que todo pensamento adulto, todos os atos posteriores de reconhecimento, são obstruídos por dificuldades inerentes ao reconhecimento de alguns aspectos fundamentais da realidade. Dentre os fatos básicos da vida, considera três como essenciais: o reconhecimento da fonte de bondade (inicialmente o seio e o leite) como sendo proveniente do mundo externo; o reconhecimento da relação sexual dos pais como sendo um ato de extrema criatividade; e o reconhecimento da passagem do tempo e da certeza da morte.

Cada um desses fatos essenciais da vida, quando negados e distorcidos, estão associados a distúrbios afetivos e de personalidade. Winnicott (1985) sugeriu que a criança pequena crê que é ela mesma quem cria o objeto que a nutre e é necessário à sua sobrevivência; um objeto nutriente que habita o seu interior. Isso seria uma distorção, mas própria de crian- ças pequenas apresentando um psiquismo ain$\mathrm{da}$ incapacitado para lidar com as ansiedades relativas à separação. No entanto, a permanência dessa distorção pode ocorrer em crianças severamente traumatizadas. Isso devido a uma impossibilidade de reconhecer que a mãe que a priva e a prejudica é também uma fonte de bondade à disposição. A psicanálise tem relacionado a incapacidade de reconhecimento da existência e do valor do outro com patologias narcísicas, com a ferida narcísica, aos ressentimentos associados a ela e às defesas utilizadas para se evitar qualquer experiência de separação.

O segundo fato da vida, ou seja, o reconhecimento da relação sexual dos pais como um ato de extrema criatividade, introduz problemas associados ao drama do incesto, ao casal em coito, ao Complexo de Édipo. A intrusão de um terceiro na relação do bebê com sua mãe coloca questões e problemas novos. O ciúme e a inveja são provocados. Porém, se tudo correr bem - se houver um ambiente capaz de ajudar a criança a processar e elaborar as experiências emocionais ligadas ao reconhecimento desse fato da vida - a questão da criatividade passa a ser simbolizada pela curiosidade da criança acerca da origem dos bebês. A criança pode então reconhecer a criatividade do casal parental e, através de identificação com eles, trilhar a própria vida criativa, incluindo as relações sexuais.

O terceiro fato da vida, ou seja, o reconhecimento da passagem do tempo e da certeza da morte, é uma característica da realidade que afeta a experiência de todos os demais fatos. Está associada ao reconhecimento de que todas as coisas e pessoas têm um fim. O reconhecimento da realidade da perda e a conseqüente experiência do luto leva, posteriormente, à necessidade de nos confrontarmos com nossos limites e com nossa mortalidade. Caso isso não seja enfrentado e elaborado, os valores humanos tornam-se distorcidos e perversos. Ser dependente é ser frágil. Se emocionar é pieguice. Envelhecer é doença. Casamento é prisão. Dentro desse contexto é que estão inseridas a pedofilia e o abuso de crianças, fruto de uma recusa do reconhecimento das diferenças sexuais e generacionais. É também a partir de uma recusa que os indivíduos se entregam, de forma acrítica, à tirania das relações sadomasoquistas. Na medida em que não se é capaz de manter, na mente, o reconhecimento de ter sido ferido e danificado ou de se 
ter ferido um outro, a violência não pode ser interrompida. Um argumento perverso pode ainda ser utilizado para manutenção da negação da crueldade: "as mulheres gostam de ser machucadas", “a criança pediu uma surra”. A violência, ao invés de ser reconhecida, passa a ser representada como um "benefício", como punições que são exercidas para o "bem".

A realidade pode ser distorcida sob o efeito do ciúme, inveja e sentimentos de exclusão experimentados em estado bruto.

\section{Notas sobre um caso}

Logo no início da sessão, o paciente reclama de seu final de semana. Menciona ter ficado muito incomodado com seu pai, que passou quase toda a tarde do sábado trancado no quarto com a namorada (companheira de vários anos). "Foi muito chato" disse ele, "me senti muito mal, eu não sabia o que fazer".

Numa associação livre de idéias, após esse relato, meu paciente trouxe um sonho ocorrido naquela noite: "Seu pai e sua mãe, cada um deles era chefe de gangs rivais de mafiosos. Estavam vestidos à caráter e caminhavam numa ruela escura, um em direção ao outro, com uma arma na mão. O meu paciente estava entre eles. Estratégica e astutamente ele se abaixou, e os tiros mataram tanto o seu pai como a sua mãe".

Em que se tornou o amor, para que um homem e uma mulher saiam dele com tamanha ira, fúria e violência? Em que se tornou o amor de um casal (pai-namorada, pai-mãe), na mente de meu paciente, para que à noite, enquanto dormia, fabricasse cenas de fúria e violência assassina?

A psicanálise tem mostrado como a criança, inundada por intensos sentimentos de inveja, ciúme e exclusão, transforma (através de projeção) o casal em um coito prazeroso num casal assassino. A incapacidade de tolerar na mente todo o amor e o ódio por esse casal que desfruta de uma relação sexual, da qual a criança não participa, libera distorções aberrantes dos fatos da vida.

Sob o efeito de uma ansiedade excessiva, produzida por uma experiência difícil de ser assimilada, meu paciente transformou o casal envolvido numa atividade prazerosa, num par de mafiosos assassinos. Uma forma de se aliviar dos sentimentos de ciúme, inveja e exclusão. Manifestações também de uma mente tentando processar a experiência emocional, atra- vés da atividade de sonhar. São muitas as distorções que podem ocorrer numa tentativa de processamento da experiência emocional. Lembro-me de uma mãe que me procurou muito assustada e ansiosa acerca do que ouviu de seu filho de cinco anos, numa conversa com o irmão mais novo: "você nem sabe o que acontece aqui em casa, à noite. A mamãe pinta a boca de vermelho, põe um vestido decotado e sai na rua dando bola para tudo quanto é homem". A mãe vadia e prostituta, ou vítima de um pai violento que a toma à força todas as noites, são variações de um mesmo tema, formas de se aliviar de sentimentos difíceis de serem assimilados, às custas de uma distorção da realidade.

Money-Kyrle (1968) salienta que essas concepções distorcidas, esses delírios inconscientes, não são apresentados somente pelos pacientes clinicamente doentes. Escreveu ele: "onde, por exemplo, eu anteriormente interpretaria um sonho do paciente como uma representação das relações sexuais dos pais, agora com mais freqüência, o interpretaria como uma representação distorcida desses eventos. De fato, parece que todas as representações imagináveis do ato sexual parental proliferam no inconsciente, exceto a correta". Ou seja, a que incluiria o reconhecimento da relação sexual como um ato de extrema criatividade, eclosão de vida e de fertilidade.

O sonho de meu paciente mostra também uma refinada evasão dos sentimentos de culpa, arrependimento e remorso, por ter, em fantasia, eliminado seus pais. Além de transformar os pais num casal mafioso, meu paciente se livrou deles, mas o seu ódio assassino, no sonho, é transformado em astúcia: "não fosse eu me abaixar, quem teria morrido seria eu”.

Aqui, fica claro como a violência se mantém e se recria constantemente, na medida em que o indivíduo lança mão de artifícios engenhosos para não reconhecê-la. Ao invés de ser reconhecida, a violência, como já mencionei anteriormente, passa a ser representada como estratégia de sobrevivência, como um "benefício", um "bem” para a humanidade.

Em trabalho recente, o psicanalista inglês John Steiner (1994), discute como Édipo enfrentou a realidade de ter matado seu pai e casado com sua mãe, nas duas peças escritas por Sófocles: Édipo Rei e Édipo em Colona.

Em Édipo Rei, ele sabia, mas fingia não saber sobre o crime que havia cometido. Quando num momento drástico fica sabendo da 
verdade, não suportando a culpa, se cega. Ato este, simbolicamente representando a destruição de sua capacidade de sentir e de perceber. Mais tarde, Édipo explica que também teria atacado os ouvidos, se tivesse sido capaz de fazê-lo: "assim eu teria privado meu sofrido corpo da audição a fim de nada mais ouvir, e nada mais ver, pois é um alivio ter o espírito invisível à causa de tão grandes males".

Em Édipo em Colona, Sófocles mostra Édipo como um velho cego à beira da morte. Dessa vez vemos uma pessoa muito diferente, lidando com a realidade de forma mais drástica, como sugeriu Steiner, retirando-se da verdade para a onipotência. Ele não nega os fatos, é tarde demais para fingir, mas ele nega qualquer responsabilidade e culpa, alegando que esses fatos foram erros cometidos contra ele e não por ele: "não quero que me atribuam como crimes, nem esse casamento, nem o assassinato de meu pai... responda apenas uma pergunta minha: se alguém aparecesse aqui neste momento, e tentasse matar-te, quererias saber se quem te ameaçava era seu pai, ou antes o castigarias? Pois esta foi exatamente a desventura com que me defrontei, levado pelos deuses".

Neste relato de Édipo, assim como no sonho de meu paciente, a responsabilidade pela morte dos pais é substituída pela frieza arrogante. Mas embora sua fala nos faça gelar por sua frieza, dá para reconhecermos também a natureza horrorosa da culpa que carrega. Podemos sentir compaixão por esse Édipo cego e vagante, na medida em que nos conscientizamos de sua quase total impossibilidade de estar em contato com sentimentos tão insuportáveis.

Quando a dor gerada pela culpa, remorso e arrependimento, beira o insuportável, podemos atacar nossa capacidade de sentir e perceber (tornamo-nos insensíveis, nos cegamos, tapamos nossos ouvidos); num movimento ainda mais drástico, transformamos a verdade em onipotência, arrogância e hipocrisia.

Lembro-me aqui de uma obra de um artista de Luanda, apresentada na última Bienal de Artes de São Paulo. Uma casa pequena, um só cômodo, com as paredes salpicadas de ferros pontiagudos. A imagem de um espaço preenchido por elementos pontiagudos sugerindo, ao se tentar penetrá-lo, riscos de perfuração mutilante, foi utilizada pelo artista para expressar o que ocorre com um país em guerra. Frente à constantes ameaças de perda de fronteiras e de identidade, disse o artista nu- ma entrevista, a Amnésia (título de sua obra) pode ser a única saída. Numa guerra, a "amnésia" é, às vezes, a única saída, o único lugar possível de abrigo, repouso, consolo.

Em texto recente Segal (1998) considera que o maior prejuízo para indivíduos inseridos em ambientes violentos é o obscurecimento do que é fantasia e do que é realidade. Num clima de constante violência (expressão de amor e ódio restrito a descargas motoras - gritos, tapas, palavras e gestos destrutivos de toda ordem) o estatuto irreal e inconsciente das fantasias, passa para o plano do "verdadeiro". Já não são mais fantasias inconscientes expressando-se e tentando ser processadas através de sonhos, mas são fatos. Não se trata mais de temores herdados filogeneticamente, não se trata mais de ficção ou sonho, mas de uma destrutividade real. Quando isso ocorre, o indivíduo terá que lançar mão de estratégias mais radicais para a sobrevivência. Eliminar o conteúdo da consciência não é suficiente para se proteger da ansiedade excessiva. O próximo estágio é a destruição do aparato mental responsável pela transformação das impressões sensoriais e das experiências emocionais em material adequado para imaginação, sonhos e pensamentos (Bion, 1992b).

A "amnésia" referida pelo artista de Luanda, é uma das conseqüências do uso desse artifício brutal, que destrói a função psíquica de transformar a experiência bruta em elementos para imaginação, sonho e pensamento. Isso, penso, explica a falta de vitalidade, de curiosidade, a falta de interesse pela vida e pela verdade, que apresentam as crianças que convivem com a violência doméstica. Ajuda-nos a entender também o comportamento oposto de algumas dessas crianças como a hiperatividade, rebeldia e agressividade extremadas; tentativas ainda de um ego tentando não cair na "amnésia", tentando se manter "vivo, lembrado, desperto".

\section{Considerações}

Trabalhos recentes dos psicanalistas Fonagy e Target (1996a, b) elucidam como a criança gradativamente vai sendo capaz de distinguir e integrar fantasia e realidade e a importância da família nesse processo. Os autores sugerem que até por volta de três anos de idade a mente não adquiriu ainda uma capacidade de discriminação entre as realidades interna e exter- 
na. Sugerem ainda que crianças pequenas utilizam basicamente duas formas de realidade psíquica: a equivalência psíquica e o "faz-deconta".

No modo de equivalência psíquica a experiência interna é equivalente e reflete a realidade externa. Por extensão o outro tem as mesmas experiências que o próprio eu. Para ilustrar esse modo de funcionamento mental os autores comentam pesquisas recentes com crianças pequenas. Quando se ofereceu às crianças uma esponja moldada e pintada para parecer uma pedra, e ao serem questionadas sobre com o que o objeto se parecia e o que realmente era, as respostas tendiam a ser as mesmas.

- “Com o que se parece este objeto?” perguntava o pesquisador, e a maioria das crianças respondia: "com uma pedra". "O que é isto?" "É uma pedra”. Pediram para que apertassem o objeto e perguntavam: "O que você acha que é?" "É uma esponja". "Com o que se parece?” E as crianças disseram: "Com uma esponja".

Crianças de três anos parecem ter dificuldades em manter na mente, simultaneamente, a aparência e a realidade. Além disso, como mostraram outras pesquisas, comportamse como se os seus pensamentos e os das outras pessoas espelhassem fielmente o mundo externo.

Mostrou-se uma conhecida caixa de doces a crianças de três anos. Cada criança esperava que a caixa estivesse cheia de doces, mas foi mostrado que estava cheia de lápis. Perguntaram então a cada criança o que seu amiguinho, que estava lá fora, achava que haveria na caixa e elas responderam com convicção: "a pessoa lá fora achará que a caixa contém lápis”.

Gradativamente o modo de equivalência psíquica vai cedendo lugar ao "faz-de-conta", ou seja, uma firme separação entre a experiência interna e a realidade externa, enquanto se brinca. Enquanto brincam as crianças são capazes de discriminar interno e externo, sabem que tudo o que estão sentindo, pensando e fazendo é só uma brincadeira. Quando param de brincar, a realidade externa volta a espelhar o mundo interno.

Segundo os autores estes modos de percepção da realidade psíquica tornam-se cada vez mais integradores, estabelecendo o que denominam de um modo reflexivo de experiência psíquica. No modo reflexivo os estados mentais podem ser representados, pois "as realidades interna e externa podem então serem vis- tas como vinculadas e, ainda assim, serem aceitas como distintas em aspectos importantes, não tendo mais que serem igualadas ou cindidas uma da outra" (1996b).

O modo reflexivo de funcionamento mental, na medida em que permite distinção e integração entre espaço interno e espaço externo é um componente importante do processo de individuação. Amplia a comunicação, pois torna possível a representação clara do estado mental do outro. Ajuda o indivíduo a atingir um nível mais elevado de intersubjetividade, e desse modo, experiências mais profundas com os outros e uma vida sentida como mais significativa. Além disso, na medida em que o modo reflexivo propicia o reconhecimento de que uma representação é só uma representação, que uma idéia é só uma idéia, e que um sentimento é só um sentimento, apresenta-se como o alicerce para o pensamento simbólico.

Como a vida em família pode facilitar ou desfavorecer esse processo?

A psicanálise vem enfatizando que o desenvolvimento de um psiquismo capaz de distinção e integração de mundo interno e externo constitui-se através de um processo intersubjetivo.

Esse processo ocorre através do mecanismo denominado por Klein (1946) de identificação-projetiva, ou seja, o processo através do qual estados emocionais provenientes da fantasia inconsciente de uma pessoa passam para outra.

Embora Klein, autora deste conceito revolucionário dentro da psicanálise, tenha ligado este fenômeno à patologia (uma defesa contra conteúdos mentais intoleráveis) Bion (1962) e mais recentemente Caper (1996) ampliaram este conceito para a esfera da normalidade.

Bion fala de uma identificação projetiva realista. O bebê, incapaz ainda de metabolizar sozinho conteúdos mentais intoleráveis, como por exemplo, suas fantasias assassinas, projeta todo o seu ódio e desprezo decorrentes desta vivência, na mãe (ou em quem cuida dele). Na medida em que o objeto externo é capaz de acolher suas fantasias, decifrá-las, nomeá-las e devolvê-las à criança de forma menos virulenta, a criança vai podendo introjetar este objeto externo e desenvolver essas funções mentais em seu interior.

Caper amplia essas idéias propondo que evocamos estados mentais na mente do outro para descobrirmos a mente do objeto externo 
e também a própria mente; uma forma de aprender dispondo das fantasias inconscientes de forma experimental; uma forma de testar o objeto externo para ver como ele é, como reage a determinadas verdades e sentimentos. Ao externalizarmos nosso mundo interno podemos também percebê-lo e reconhecê-lo.

A questão que se coloca, segundo Caper (1996), é: “O que acontecerá se eu fizer isso para ele? Se eu fizer com que ele sinta o que sinto, o que ele fará? Ele irá explodir, isto é, o que estou projetando é explosivo? Ele achará isso agradável, aborrecido, incompreensivel, ou seja, o que estou projetando é agradável, aborrecido, incompreensivel? A resposta do receptor informa ao projetor a respeito de sua projeção, um aspecto de sua realidade interna.

Todas as crianças têm, por exemplo, fantasias assassinas. Imaginemos, então, que no movimento inconsciente de experimentá-las, testá-las, informar-se a respeito delas, através de identificação projetiva, a criança simule uma luta com o pai. Imaginemos que a criança diga a ele: "Vocêé um monstro, você tem que ficar aí parado para que eu possa matá-lo". Se o pai continuar a brincar e deixar-se morrer para então ressuscitar em seguida de forma lúdica, poderá estar ajudando a criança a metabolizar e a elaborar suas fantasias edípicas assassinas.

Suponhamos, no entanto, que o pai interrompa a brincadeira numa atitude violenta de reprovação, tristeza, raiva ou medo. Experiências repetidas deste tipo podem reforçar a idéia da criança de que sua fantasia pode se tornar demasiadamente real.

Um casal que se agride constantemente e que manifesta pouco apreço à vida sexual pode, por sua vez, alimentar e tornar demasiadamente real a fantasia da criança de um casal violento e arruinado. Fantasia esta, proveniente de uma impossibilidade da criança, ou por ciúmes, ou por inveja, ou por intenso sentimento de exclusão, de reconhecer a relação sexual dos pais como um ato de extrema criatividade.

Quando a realidade externa se torna uma réplica da realidade interna, a identificaçãoprojetiva deixa de ser, como sugeriu Caper (1996), instrumento de experimentação e passa a ser utilizada como uma defesa, uma forma de se livrar de conteúdos mentais vividos como intoleráveis, pois não se pode mais vivenciar as projeções como experimentações de conseqüências limitadas, mas como alterações plenas e catastróficas da realidade externa.
Fica claro, a partir dessas idéias, que a criança é extremamente vulnerável às representações de si mesma feitas pelos objetos externos. Há como que uma total dependência ao objeto externo para representar seu mundo interno e ajudá-la a processá-lo e elaborá-lo.

É por isso que Fonagy e Target (1996b) enfatizam que a atitude dos pais é crucial nesse processo e que o estado mental da criança deve ser representado de maneira suficientemente clara e acurada e de forma lúdica. Quando os pais são bem sucedidos nessa tarefa, abrem caminho para que a criança possa pensar as próprias experiências mentais, as próprias representações mentais que são muito reais e ainda assim não são reais. Isto permite uma atitude lúdica e flexível a respeito da realidade em busca de modos confortáveis de conviver com ela.

Mas quando a dinâmica familiar torna-se uma réplica das fantasias inconscientes, o plano dos significados fica impedido de se desenvolver e o nível do simbólico não pode ser alcançado. Sem os significados que podem alcançar sua representação em símbolos, a experiência emocional não pode ser pensada e evoluir. Assim, encontramos famílias que fundamentalmente "encenam" as diversas tramas familiares tão bem narradas pela mitologia. Pais que tal qual Cronos, "devoram" seus filhos ao nascer. Mães que, assim como Rheia, num pacto silencioso e perverso com seus maridos, permitem que seus filhos sejam devorados, ou seja, impedidos de crescer e de se individuar. Filhos que, tal como Édipo, assassinam os pais e se "casam" com suas mães. Irmãos que, assim como Caim e Abel, entranham-se sem saída numa rivalidade mortífera. Já não são mais fantasias inconscientes filicidas, fratricidas ou parricidas: é o "ato" tomando conta do cotidiano da vida familiar e sendo encenado até às últimas conseqüências, gerando distorções aberrantes dos fatos da vida.

Nessa perspectiva podemos pensar que a violência doméstica aponta não só para uma dinâmica viciosa de privação e traumas mas, essencialmente, para uma falta de experiências emocionais que possam ser significadas e alcançar representações em símbolos. A violência doméstica aponta para uma profunda incapacidade de seus membros para viverem as emoções e pensá-las de forma a propiciar uma integração permanente de novas experiências que ampliam a possibilidade de conhecimento. 
A formação de profissionais que trabalham com famílias nas áreas de saúde, educação ou social, tem me mostrado o quanto essas famílias podem ser ajudadas na recuperação das funções mentais suprimidas, de modo a interromper o circuito vicioso de violência e de defesas contra reconhecê-la.

A possibilidade de estarem todos juntos, sendo ao mesmo tempo testemunhas e participantes do relato de cada um, abre um espaço profícuo para o reconhecimento de um modo de funcionamento grupal, onde o outro é uma réplica do próprio eu, onde o externo espelha o interno, onde fantasia e realidade estão embassadas e distorcidas.

No entanto, a complexidade da tarefa exigida do profissional pressupõe muito estudo teórico, supervisão e auto-conhecimento. Alvo das identificações-projetivas da família, o profissional terá que ser capaz de acolhê-las, decifrá-las, nomeá-las, propiciando assim que as experiências emocionais provenientes das fantasias inconscientes possam ser pensadas e evoluídas, ao invés de "encenadas" com violência.

\section{Referências}

Bion WR 1962. Aprendendo com a Experiência. Rio de Janeiro, Imago, 1991.

Bion WR 1992a. Emotional violence. In Cogitations. Karnac Books, Londres.

Bion WR 1992b. Animism, destructive attacks and reality. In Cogitations. Karnac Books, Londres.

Caper R 1996. O brincar, a experimentação e a criatividade. Livro Anual de Psicanálise, XII, Escuta, São Paulo.

Fonagy P \& Target M 1996a. Brincando com a Realidade I: Teoria da mente e o desenvolvimento normal da realidade psíquica. Livro Anual de Psicanálise, XII, 11, Escuta, São Paulo.

Fonagy P \& Target M 1996b. Brincando com a Realidade II: O desenvolvimento da realidade psíquica a partir de uma perspectiva teórica. Livro Anual de Psicanálise, XII, 65, Escuta, São Paulo.

Klein M 1946. Notas sobre alguns mecanismos esquizóides. In Os Progressos da Psicanálise. Rio de Janeiro, Zahar, 1978.

Money-Kyrle R 1971. The aim of psycho-analysis. Int Journal of Psycho-analysis 52: 103-106.

Segal H 1998. Psicanálise, Literatura e Guerra. Imago, Rio de Janeiro.

Steiner J 1997. Dois tipos de organização patológica em Édipo Rei. In Refúgios Psíquicos. Imago, Rio de Janeiro.

Winnicott DW 1985. O Ambiente e os Processos de Maturação. Artes Médicas, Porto Alegre 1990. 